\title{
Population dynamics in northwestern China
}

\author{
Xueyan Yang ${ }^{1}$ (D) Wanxin $\mathrm{Li}^{1} \cdot$ Wen Jing $^{1} \cdot$ Chezhuo Gao $^{1} \cdot$ Rui Li $^{1} \cdot$ Yuqi He $^{1}$
}

Received: 26 May 2021 / Accepted: 22 June 2021 / Published online: 27 July 2021

(c) The Author(s) 2021

\begin{abstract}
This article analyzes the population dynamics in northwestern China from roughly 2010 to 2020. The area's dynamics showed a slow, stable increase in population size, a stable increase in the population of non-Han ethnic groups, which increased at a more rapidly than the Han population, and population rejuvenation coupled with a population structure that aged. The biological sex structure fluctuated within a balanced range in northwestern China. Urbanization advanced in northwestern China, throughout this period, but the area's level of urbanization is still significantly lower than the average level of urbanization nationally.
\end{abstract}

Keywords Fertility $\cdot$ Ethnic structure $\cdot$ Age structure $\cdot$ Urbanization · Northwestern China

\section{Introduction}

Population dynamics refers to the development of and changes in the size, structure, and distribution of a population during a certain period of time and in a certain space (Arsdale, 1978; Brea, 2003; Jorgenson \& Burns, 2007; Iburg, 1999). Population size represents the basic change in population and involves three important life events: birth, death, and migration. Change in population size results from the interaction between birth rate, death rate, and population migration, and finally has the status of growth, decline, or balance (Calhoun, 1952; Nobles et al., 2015). Population structure includes classifications of natural qualities such as biological sex structure, age structure, ethnic structure, and by social qualities such as religious structure, professional structure, and educational structure. Among these structures, biological sex structure and age structure are the key contents of population studies (Arsdale, 1978; Chalmers \& Joseph, 2010). Population is distributed between urban and rural areas, and population migration between the countryside and cities or from

Xueyan Yang

xueyanyang@mail.xjtu.edu.cn

1 Institute for Population and Development Studies, School of Public Policy and Administration,

Xi'an Jiaotong University, Xi'an, China 
one region to another affects population distribution. The distribution of population between urban and rural areas reflects the level of urbanization ( $\mathrm{Li} \& \mathrm{Liu}, 2013$; Hinde, 2002).

The existing research on population dynamics in northwestern China is insufficient and sporadic, and is focused mostly on limited areas (e.g. Xinjiang) or ethnic minority groups. While northwestern China consists of three provinces (Shaanxi, Gansu, Qinghai) and two autonomous regions (Xinjiang, Ningxia) comprehensive studies of the entire northwest are lacking. Such studies are necessary to provide an overall picture of population dynamics in northwestern China. Therefore, this study considers northwestern China as a whole, and presents data and a descriptive analysis of five aspects of population dynamics including population size, ethnic structure, age structure, biological sex structure, and the distribution of population between urban and rural areas.

\section{Data and methods}

The study used data gathered from the Fifth National Population Census (2000), the National 1\% Population Sample Surveys in 2005, the Sixth National Population Census (2010), the National 1\% Population Sample Surveys in 2015, the bulletin of Seventh National Population Census (2020), nationwide survey data on fertility from 2017, China Statistical Yearbooks from 2011 to 2020, China Population and Employment Statistical Yearbook from 2011 to 2020, and 2019-2020 statistical yearbooks for the three provinces (Shaanxi, Gansu, Qinghai) and two regions (Xinjiang, Ningxia). Descriptive analysis and a comparative analysis were the methods adopted to analyze population dynamics from 2010 to 2019 in northwestern areas and nationwide. With respect to population size, indicators for total fertility rate (TFR) and population quantity were used to measure fertility level and general population dynamics. With respect to the population structure of ethnic groups, the TFR and the population quantity of ethnic groups were adopted for measuring ethnicity dynamics. Total population was divided into age groups to determine age structure, and the child dependency ratio (CDR), old-age dependency ratio (ODR), and total dependency ratio (TDR) were used to measure the degree of aging and social dependency burdens. With respect to biological sex structure, sex ratio at birth (SRB) and the sex ratio were the indicators adopted to assess gender development and gender balance in the population. With respect to the distribution of population between urban and rural areas, urbanization rate was the indicator selected to measure the degree of urbanization. 
3.50

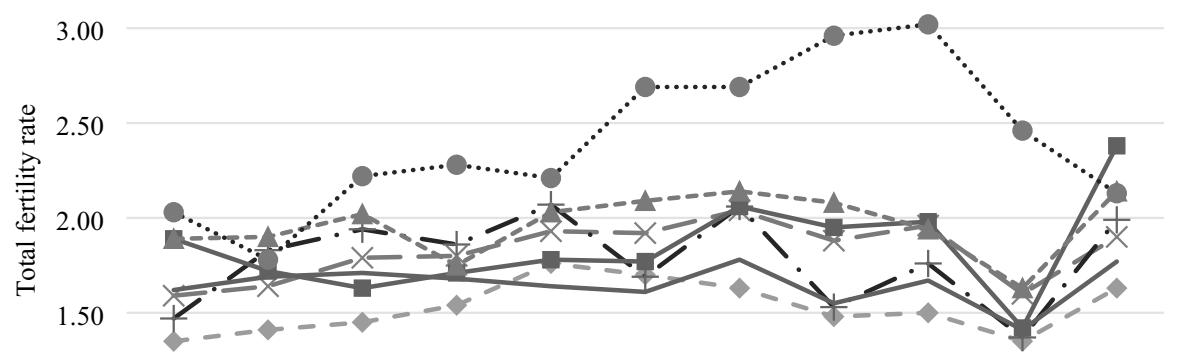

1.00

0.50
$\begin{array}{lllllllllll}2006 & 2007 & 2008 & 2009 & 2010 & \begin{array}{c}2011 \\ \text { Year }\end{array} & 2012 & 2013 & 2014 & 2015 & 2016\end{array}$
$\rightarrow-$ Five northwestern provinces and regions $\quad->-$ Shaanxi province
-十. - Gansu province
$-\mathbf{-}$ - Qinghai province
- Ningxia autonomous region
... Xinjiang autonomous region

Fig. 1 TFR for the five northwestern provinces and regions from 2006 to 2016. Note: The TFR information shown in figure is based on data for the five northwestern provinces and regions provinces taken from the 2017 Nationwide Survey Data on Fertility (Data about the national TFR are taken from the article" China fertility status report, 2006-2016: an analysis based on 2017 China fertility survey" (He et al. 2018)

\section{Results}

\subsection{Population dynamics in northwestern China: fertility level and population size}

The Total Fertility Rate shows the fertility level of women of childbearing age. It can be seen from Fig. 1 that, overall, the TFR of the five northwestern provinces and regions fluctuated relatively smoothly from 2006 to 2014, with the rate for the region as a whole remaining above 1.6. From 2006 to 2012, the general trend showed a slow rise, with TFR for the region reaching a peak of 2.04 in 2012. After that, there was a steep decline in 2015, with TFR dropping to 1.60. In 2016, the rate rose again to a high of 1.90. It is possible that people's belief in the traditional Chinese zodiac had an impact on fertility decisions, with TFR reaching its high point during the year of the Dragon in 2012 and a low point during the year of the Goat in 2015.

Looked at individually, the TFRs of Shaanxi Province, Gansu Province, Ningxia Hui Autonomous Region, and Qinghai Province had similar trends. During the period 2006-2015, all four rose slowly and then fell, reaching their lowest points in 2015; all rebounded strongly in 2016. The TFR of the Xinjiang Uygur Autonomous 
Region was the highest among the five northwestern provinces and regions. It rose from 2006 to 2014, reaching a peak of 3.02 in 2014 before falling back. In 2016, Xinjiang's TFR was 2.13.

Table 1 shows the changing population trends for the five northwestern provinces and regions from 2010 to 2020 . The total population of the five northwestern provinces and regions taken together showed a slow upward trend for the ten year period, from 96.69 million in 2010 to 103.53 million in 2020, exceeding 100 million for the first time in 2015. Looked at individually, the total population of each province or region was relatively stable, in most cases showing slow increases during the ten year study period. The total population of Shaanxi Province was over 38 million, making it the most populous province among the five northwestern provinces and regions. Gansu Province was the second most populous with a total population of about 26 million, but lost almost 1.5 million people between 2019 and 2020. The total population of Xinjiang Uygur Autonomous Region also increased, growing from 21.81 million in 2010 to more than 25 million in 2020. Ningxia Hui Autonomous Region and Qinghai Province had similar population totals in 2020, with about 6 million in Qinghai and about 7 million in Ningxia.

\subsection{Fertility rate by ethnic groups and ethnic structure}

Figure 2 shows a comparison of the TFRs for the Han ethnicity and ethnic minority groups in northwestern China from 2006 to 2016. In general, the total fertility rate of ethnic minority women of childbearing age was significantly higher than that of Han women. The trend of the TFR for ethnic minority women of childbearing age decreased at first and then increased from 2.33 in 2006 to its peak of 3.27 in 2013 . After that, the TFR for minority women decreased annually to 2.32 in 2016. The TFR of Han women of childbearing age increased slightly from 1.38 in 2006 to 1.57 in 2014, and then jumped sharply to 1.78 in 2016 when the Universal Two-child Policy was introduced.

Table 2 shows the ethnic minority population and Han population for Ningxia Hui Autonomous Region, Qinghai Province, and Xinjiang Uygur Autonomous Region from 2010 to 2018. Figure 3 shows a comparison of trends of the proportion of total population occupied by ethnic minority groups in Ningxia, Qinghai, and Xinjiang from 2010 to 2018 . Both the ethnic minority population and the Han population in Ningxia Hui Autonomous Region increased annually. The ethnic minority population increased from 2.23 million in 2010 to 2.57 million in 2018, accounting for nearly $40 \%$ of the total population in Ningxia, while the Han population increased from 4.1 million in 2010 to 4.31 million in 2018 , outnumbering the ethnic minority population throughout the study period. The population in Qinghai Province also increased steadily during the study period. The Han population grew from 2.99 million in 2010 to 3.15 million in 2018 , while the ethnic minority population increased from 2.65 million in 2010 to 2.88 million in 2018, accounting for nearly $50 \%$ of Qinghai's total population. The Han population in the Xinjiang Uygur Autonomous Region grew steadily from 2010 to 2015 , and then declined each year after that. overall showing a downward trend from 8.32 million in 2010 to 7.86 million 


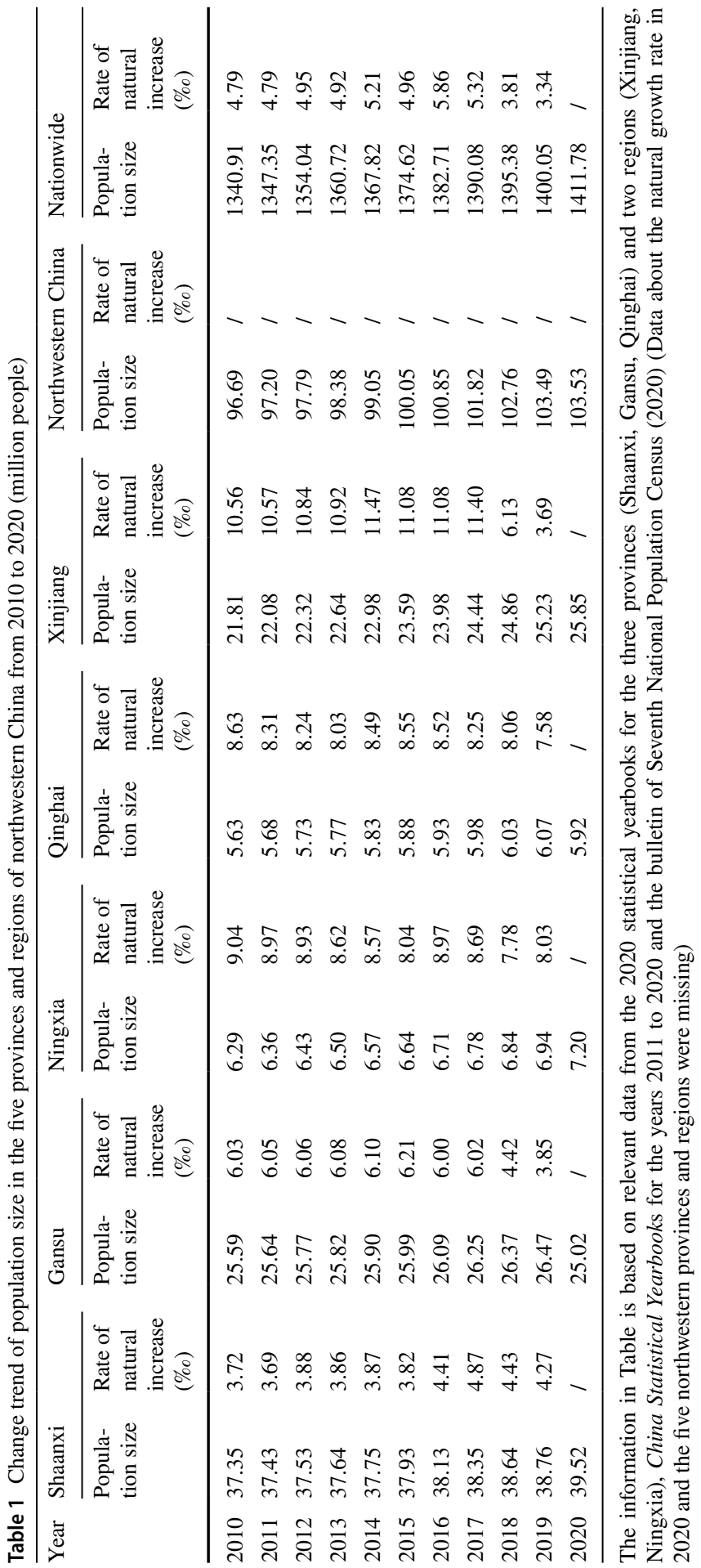




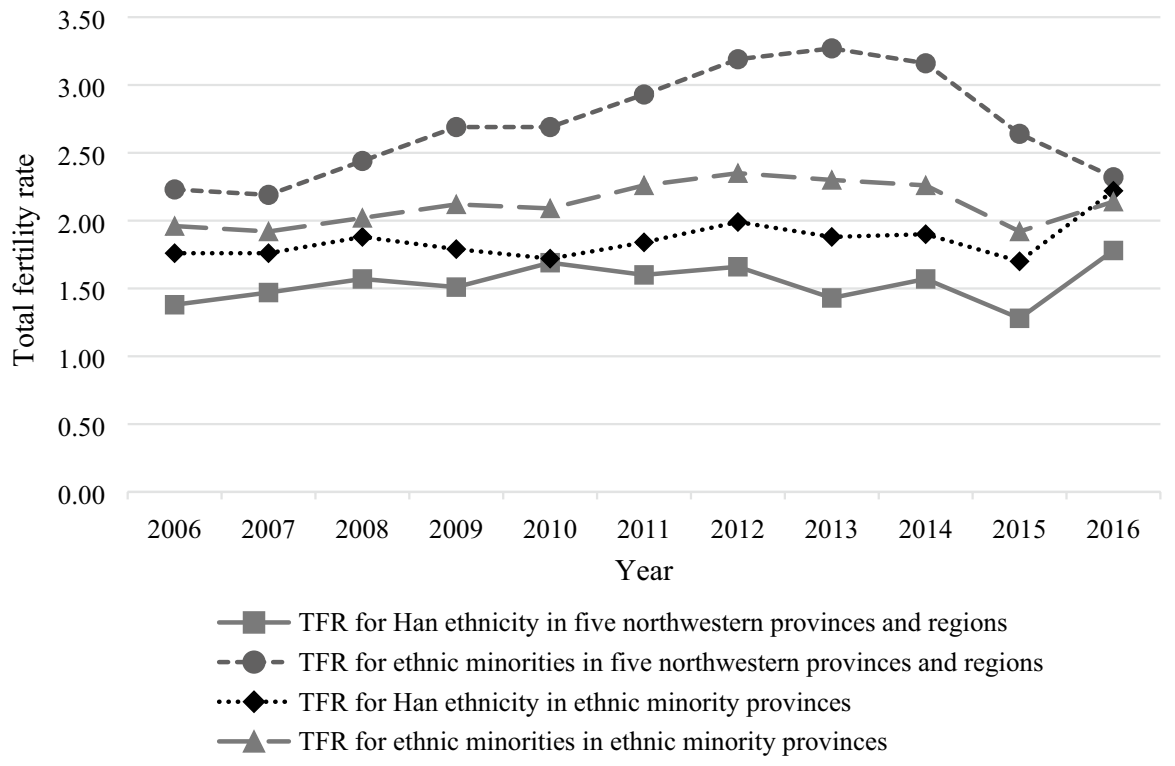

Fig. 2 Comparison of the TFRs for Han and ethnic minorities in Northwestern China and ethnic minority provinces from 2006 to 2016 (Data about the national TFRs for for Han and ethnic minorities were missing, so we quote data from the article"Fertility levels and trends in China's ethnic minority provinces, 2006-2016: based on 2017 China fertility survey") (Yuan et al. (2019)). Note: The presentation in figure is based on data for the five northwestern provinces and regions taken from the 2017 Nationwide Survey Data on Fertility

in 2018. The number of ethnic minorities increased annually, from 13.32 million in 2010 to 14.98 million in 2018, accounting for more than $60 \%$ of the total population in Xinjiang and outnumbering the Han population. ${ }^{1}$

\subsection{Age structure of the population and the social dependency ratio}

Figure 4 shows the trend for the age structure of the population in northwestern China from 2010 to 2020 . The total population of the region grew annually over the 11 -year period, rising from 96.65 to 103.53 million people. There were 72.04 million people aged 15-64 in 2010. The population in this age group increased from 2010 to 2018 , peaking at 74.26 million people in the year, after which it decreased to 71.69 million people in 2020. In 2010, there were 17.19 million people aged 0-14. After a slight declines in 2011 and 2012, there was a growth from 2013 to 2020, with the number of people in this age group at 20.21 million in 2020 . The population aged 65 or more grew annually over the 11 -year period, from 7.39 million people in 2010 to 11.63 in 2020. In terms of the proportion of total population by age groups, $74.54 \%$ of the population was aged 15-64 and of working age in 2010. This

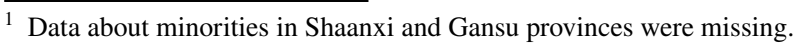




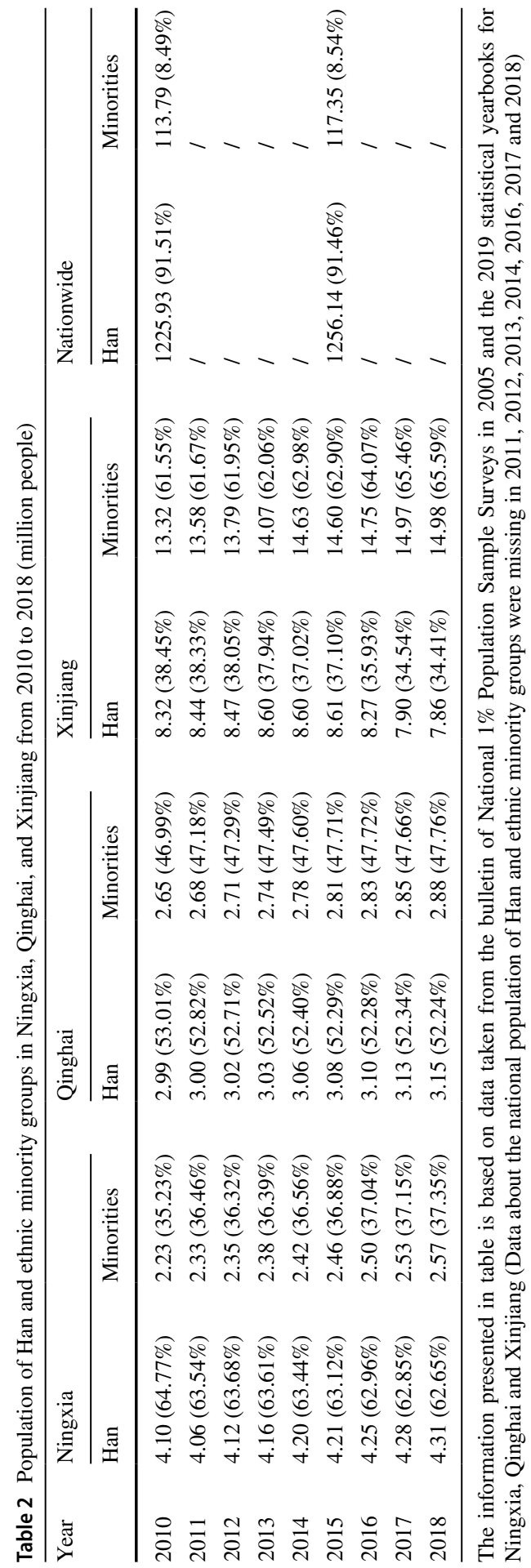




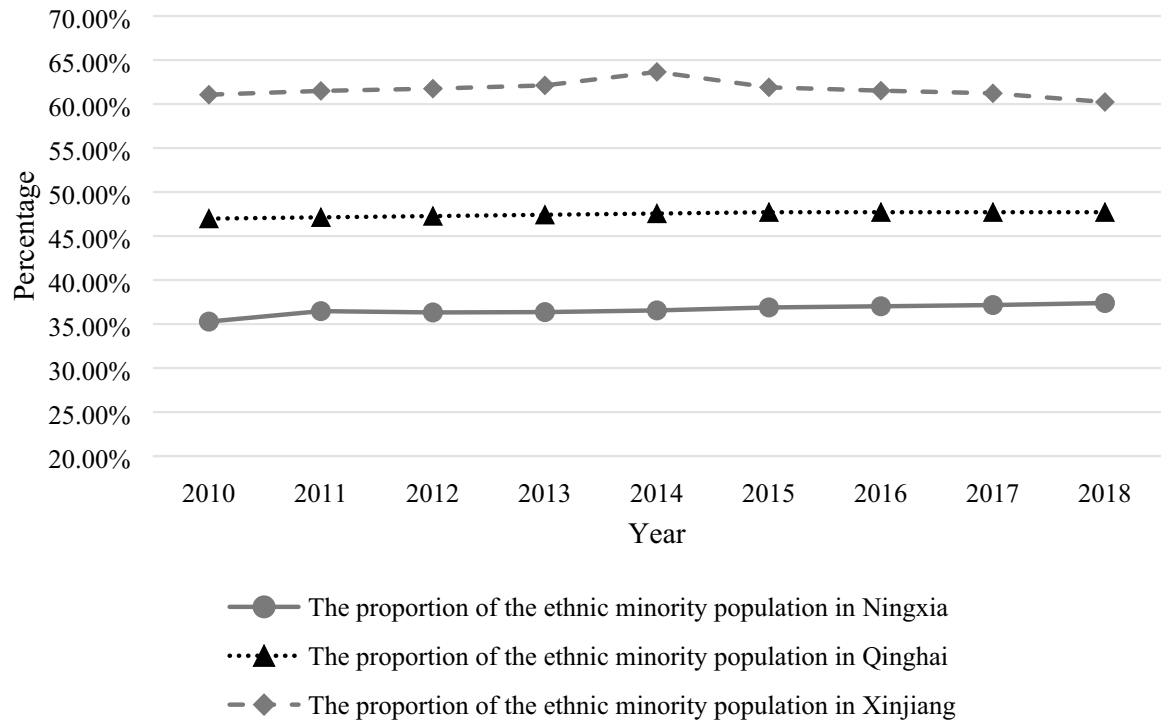

Fig. 3 The comparison of trends for the proportion of total population occupied by minority ethnic groups in Ningxia, Qinghai and Xinjiang from 2010-2018. Note: The presentation in figure is based on data taken from the 2019 statistical yearbooks for Ningxia, Qinghai and Xinjiang

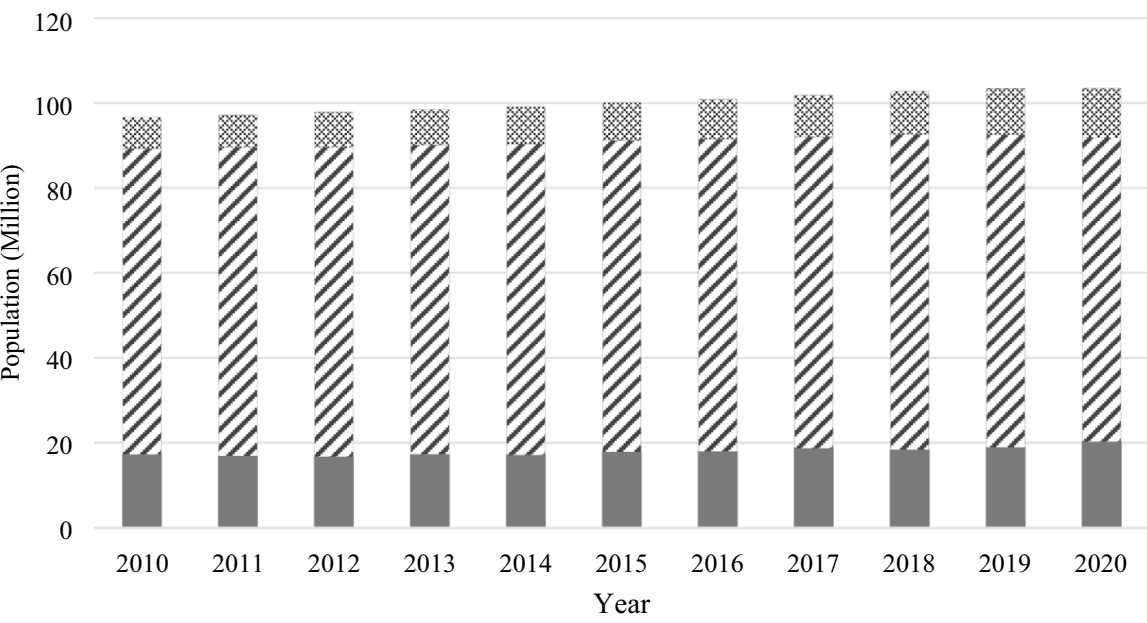

People aged 0-14 $/$ People aged 15-64 $\gg$ People aged 65 or more

Fig. 4 Trend for the Age Structure of Population in Northwestern China from 2010 to 2020. Note: The presentation in figure is based on data taken from China Statistical Yearbooks for the years 2011-2020 and from the bulletin of the Seventh National Population Census (2020) 


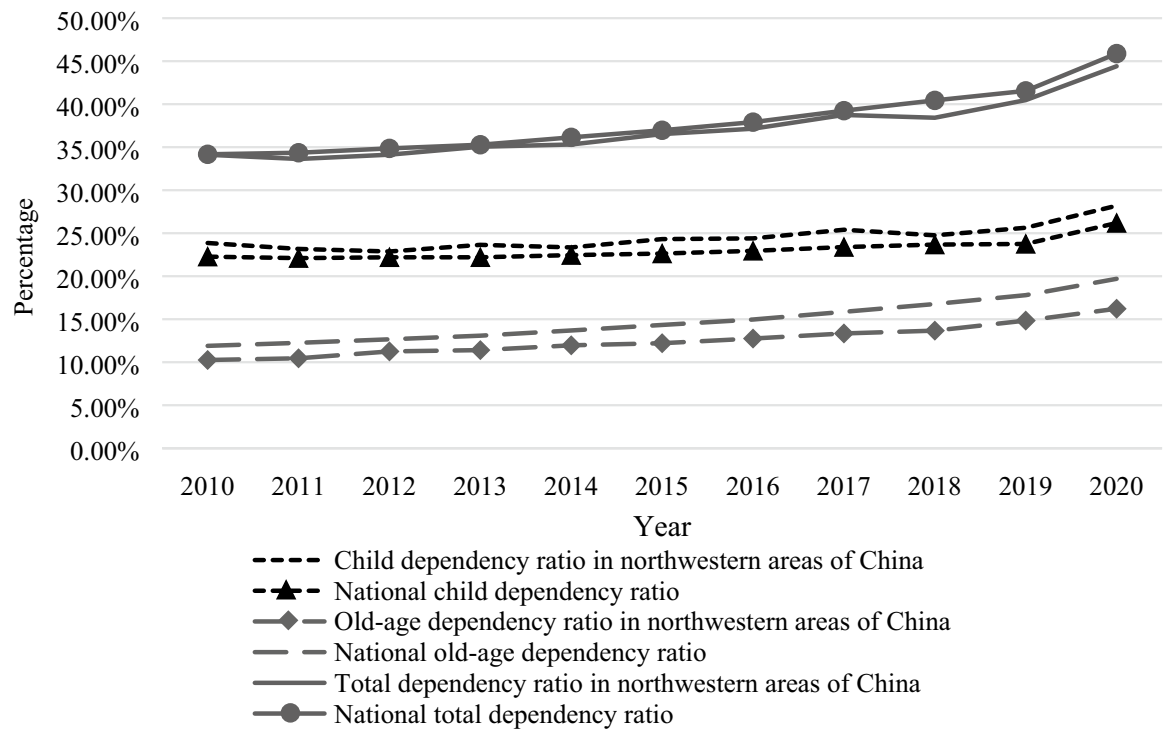

Fig. 5 Trend for the Social Dependency Ratio in Northwestern China from 2010 to 2020. Note: The presentation in figure is based on data from China Statistical Yearbooks for the years 2011-2020 and from the of the bulletin of Seventh National Population Census (2020)

percentage remained stable from 2010 to 2013 and then declined from 2014 to 2020 , ending at $69.24 \%$. In 2010, people aged 0-14 made up $17.79 \%$ of the total population and people aged 65 or more $7.65 \%$. These percentages had increased to $19.52 \%$ and $11.23 \%$, respectively, in 2020 .

Figure 5 shows the trend for the social dependency ratio in northwestern China from 2010 to 2020 . The total dependency ratio grew from $34.12 \%$ to $44.41 \%$ over the 11-year period covered in this study. The total dependency ratio for China as a whole grew from $34.17 \%$ to $45.88 \%$ during the same 11 -year period. The dependency ratio for the northwestern China maintained almost the same level as the national total dependency ratio. The child dependency ratio in northwestern areas of China increased from $23.86 \%$ in 2010 to $28.19 \%$ in 2020 and was higher throughout this period than the national child dependency ratio, which went from $22.27 \%$ in 2010 to $26.18 \%$ in 2020 . The old-age dependency ratio in northwestern China increased from $10.26 \%$ in 2010 to $16.22 \%$ in 2020 , remaining lower throughout the period thanthe national old-age dependency, which stood at $11.90 \%$ in 2010 and $19.70 \%$ in 2020 .

\subsection{Biological sex structure and population equality in northwestern China}

From 2000 to 2015, the overall situation of sex ratio at birth in the five northwestern provinces and regions improved. The ratio in Shaanxi Province dropped rapidly from 124.66 in 2000 to 109.63 in 2015 , indicating that the sex ratio in the province returned to a normal range. The sex ratio at birth in Gansu Province 


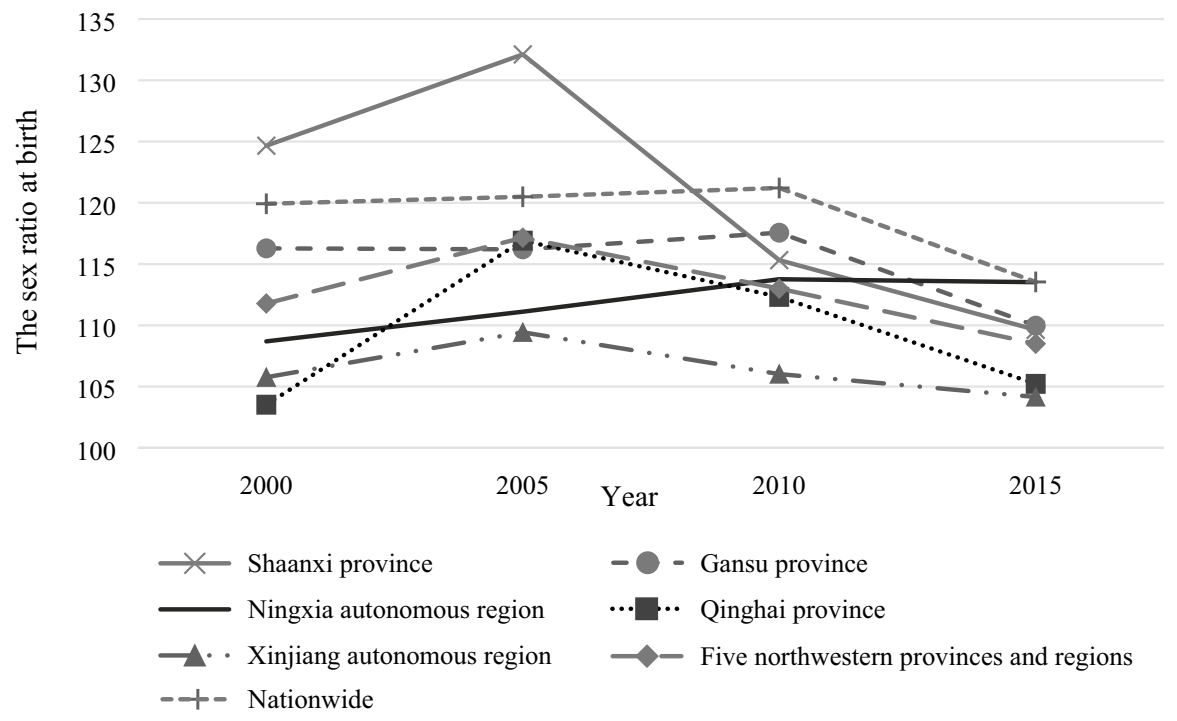

Fig. 6 Trends of sex ratio at birth in the five northwestern provinces and regions. Note: The presentation in figure is based on data taken from the Fifth National Population Census (2000), the Sixth National Population Census (2010), the National 1\% Population Sample Surveys in 2005, the National 1\% Population Sample Surveys in 2015 and the bulletin of Seventh National Population Census (2020)

rose from 116.28 in 2000 to 117.56 in 2010, and then dropped to 109.97 in 2015 , showing a slow declining trend. The sex ratio at birth in Ningxia Autonomous Region showed an overall upward trend, from 108.69 in 2000 to 113.52 in 2015 , indicating that the sex ratio at birth deviated gradually from the normal range. In Qinghai Province, the sex ratio at birth fluctuated, but stayed within the normal range except when it rose to 116.91 in 2005. The sex ratio at birth in Xinjiang Province did not change significantly, staying in a normal range throughout the period (Fig. 6).

Figure 7 shows that the sex ratio in Shaanxi Province remained around 106 from 2010 (106.9) to 2017 (106.44), dropping to 100.47 in 2018, and rapidly increasing to 104.79 in 2020 . This shows that the development of the biological sex structure of the population in Shaanxi Province was unequal. The sex ratio in Gansu Province dropped from 104.42 in 2010 to 103.1 in 2020, indicating that the biological sex structure of the population in Gansu Province was in a healthy state of development. The situation was the same in Ningxia Hui Autonomous Region, with the sex ratio dropping from 105.09 in 2010 to 103.83 in 2020. Qinghai Province had relatively high ratios in 2010 and 2018, but other years showed a balanced development. From 2010 to 2018, the sex ratio in Xinjiang Uygur Autonomous Region showed a noticeable downward trend from 106.87 in 2010 to 99.76 in 2018 , but then increased rapidly to 106.85 in 2020 . This indicates that the biological sex structure of the population in Xinjiang showed an uneven development. 


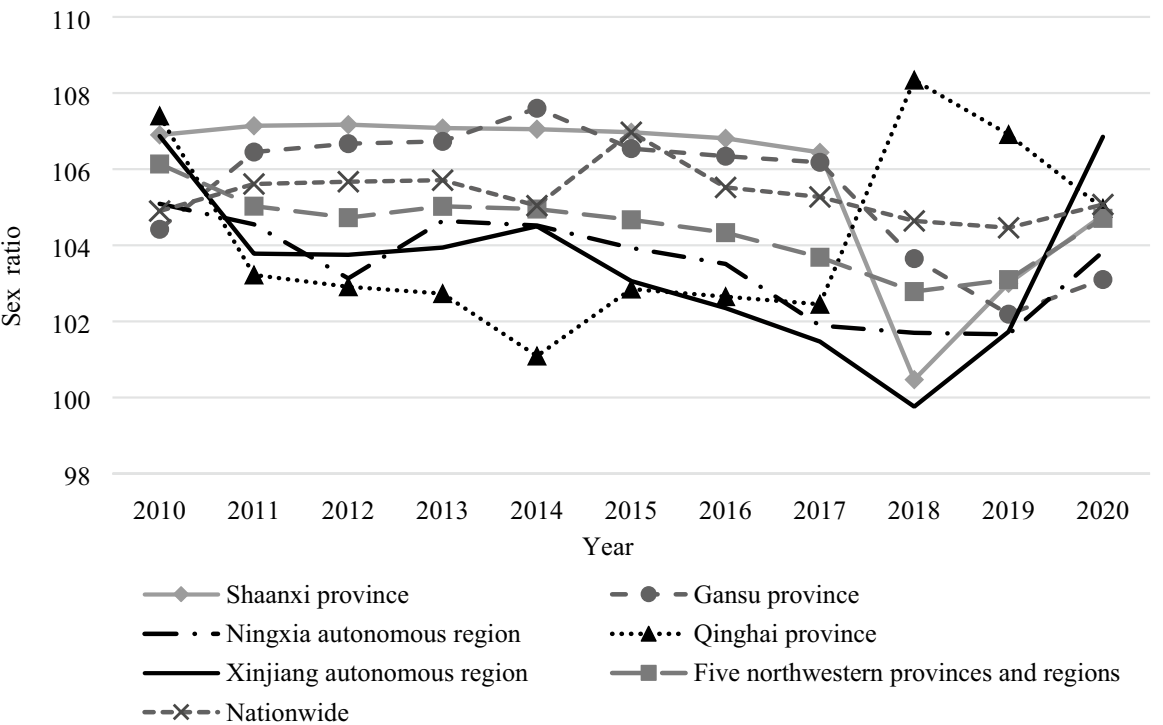

Fig. 7 Trends for the sex ratio in the five northwestern provinces and regions. Note: The presentation in figure is based on data taken from the China Population and Employment Statistical Yearbook for the years 2011-2020, 2019 statistical yearbooks for Ningxia and the bulletin of Seventh National Population Census (2020)

\subsection{The urbanization process}

Figure 8 shows trends for the urban-rural structure of the population in the five northwestern provinces and regions from 2010 to 2019. After 2010, the permanent urban population of the five northwestern provinces and regions increased annually, while the permanent rural population decreased. The rates of increase and decrease in northwestern China were roughly the same as national rates during this time period. By the end of 2016, the permanent urban population of the five northwestern provinces and regions had increased from 41.21 million in 2010 to 51.22 million. With the urban population standing at $50.77 \%$ of the total population (the urbanization rate of the permanent population), the permanent urban population surpassed the permanent rural population for the first time. By the end of 2019, the permanent urban population of the five northwestern provinces and regions had reached 56.50 million, and the proportion of the total population (the urbanization rate of the permanent population) stood at $54.59 \%$, an increase of 1.05 percentage points from the end of the previous year.

Figure 9 shows the urbanization rate of permanent residents for the five northwestern provinces and regions, and for northwestern China as a whole from 2010 to 2019. During this 10 year period, the trend for the urbanization rate of permanent residents in the five northwestern provinces and regions was steadily upward. As of the end of 2019, the urbanization rate of the permanent population in Ningxia had increased from $47.96 \%$ in 2010 to $59.86 \%$, and Ningxia ranked first among the 


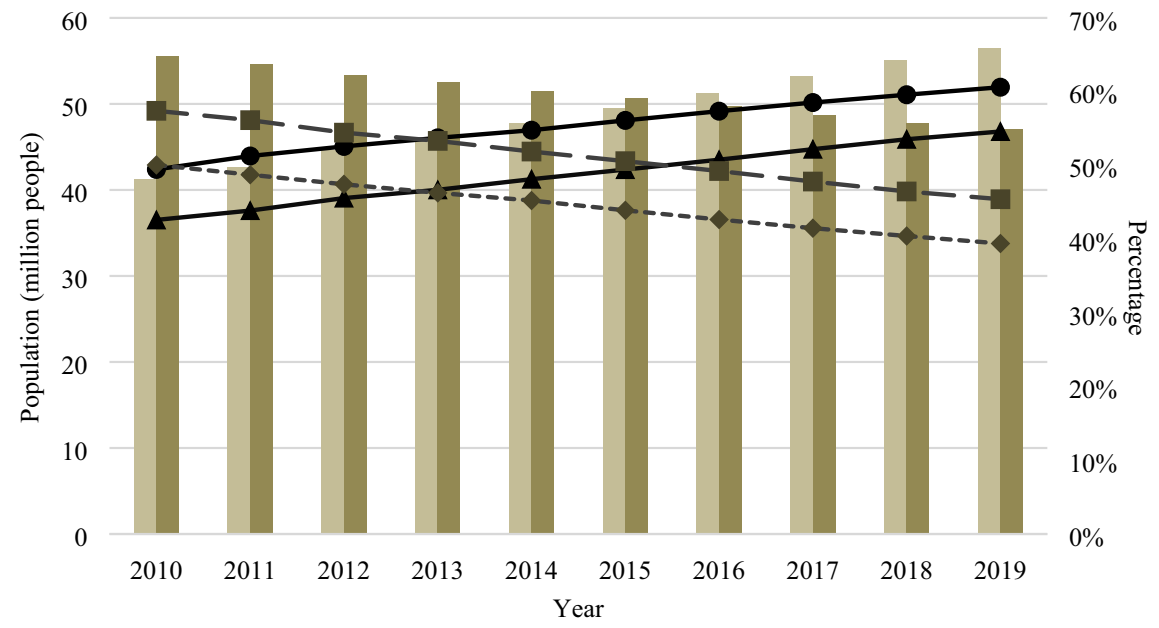

Number of permanent residents in urban areas in five northwestern provinces and regions

Number of permanent residents in rural areas in five northwestern provinces and regions

- - proportion of permanent residents in urban areas in five northwestern provinces and regions

- proportion of permanent residents in urban areas nationwide

- proportion of permanent residents in rural areas in five northwestern provinces and regions

$-\downarrow$ - proportion of permanent residents in rural areas nationwide

Fig. 8 Trends in the urban-rural structure of the population from 2010 to 2019. Note: The data presented in this figure was taken from the 2020 China Statistical Yearbook and 2019 and 2020 statistical yearbooks for the five northwestern provinces and regions

five provinces and regions. The urbanization rate of permanent residents in Shaanxi increased from $45.70 \%$ in 2010 to $59.43 \%$ in 2019 , ranking the province second. In Qinghai, the urbanization rate increased from $44.72 \%$ in 2010 to $55.52 \%$ in 2019, ranking the province third. The urbanization rate of permanent residents in these three areas was higher throughout the period than it was in the five northwestern provinces and regions as a whole. The urbanization rate of the permanent population in Xinjiang was $42.79 \%$ in 2010, and was higher than that of the five northwestern provinces and regions as a whole $(42.60 \%)$ in the same year. However, after 2011, the increase of the urbanization rate of the permanent population in Xinjiang slowed, reaching 51.87 at the end of 2019, ranking Xinjiang fourth. Except for 2010, Xinjiang's rate was lower than that the five northwestern provinces and regions as a whole for the remainder of the period. The urbanization rate of the permanent population in Gansu increased from $36.12 \%$ in 2010 to $48.49 \%$ in 2019, ranking Gansu fifth. The rate in Gansu was lower than that of the five northwestern provinces and regions as a whole for the entire ten year period.

\section{Discussion and conclusion}

The above analysis highlights several key characteristics of population dynamics in northwestern China. 


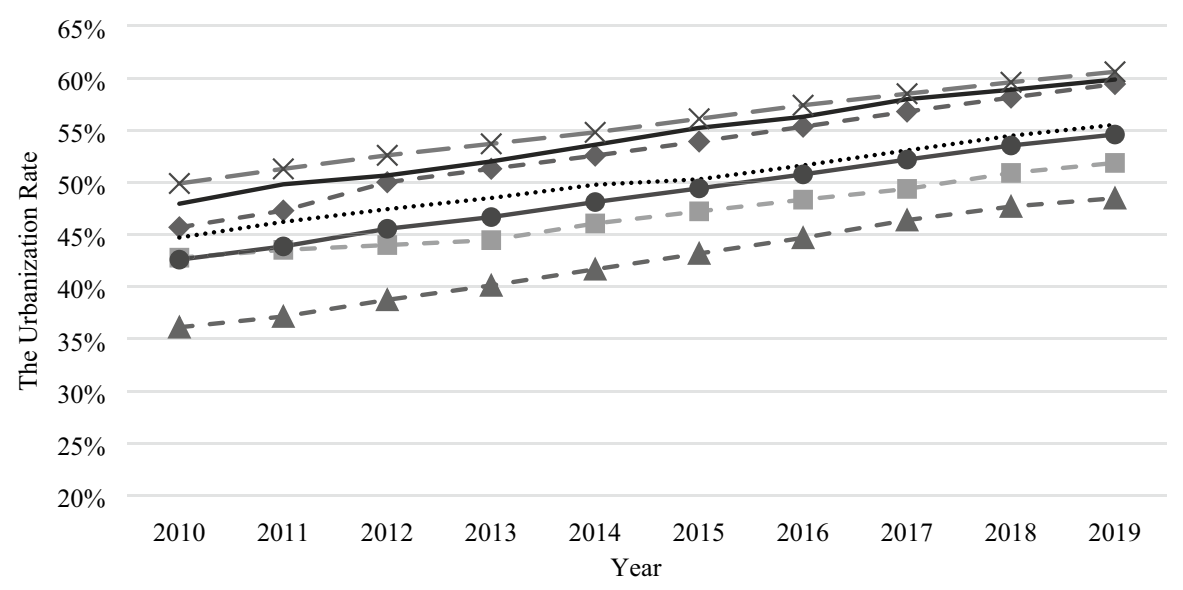

- - the urbanization rate of permanent residents in Shannxi province

- $\triangle$ - the urbanization rate of permanent residents in Gansu province

— the urbanization rate of permanent residents in Ningxia autonomous region

....... the urbanization rate of permanent residents in Qinghai province

- - the urbanization rate of permanent residents in Xinjiang autonomous region

- the urbanization rate of permanent residents in five northwestern provinces and regions

$x-$ National urbanization rate of permanent residents

Fig. 9 Trends for the urbanization rate of permanent residents from 2010 to 2019. Note: The data presented in this figure was taken from the 2020 China Statistical Yearbook, 2020 China household survey and 2019 and 2020 statistical yearbooks for the five northwestern provinces and regions

\subsection{A slow, stable increase in the population size in northwestern China}

From 2006 to 2015, the TFR among women in northwestern China first increased then decreased, and then in 2016, TFR rebounded with the introduction of the Universal Two-child Policy. The TFR in the Xinjiang Autonomous Region was at a higher level compared with other provinces and autonomy regions, nearing two in 2016, while TFR in Shaanxi Province was at the lowest level among three provinces and two autonomy regions. The Universal Two-child Policy helped to move the TFR higher in Shaanxi, Gansu and Qinghai provinces, and Ningxia Autonomous Region, but had no apparent impact on the TFR in Xinjiang Autonomous Region. From 2010 to 2020, the population of northwestern China increased slowly, passing 100 million by the end of the period. Shaanxi Province with almost 39.6 million people had the largest population.

\subsection{Stable growth of the ethnic minority population, which increased in size more rapidly than the Han population}

As a result of different family planning policies for ethnic minorities and Han populations, from 2006 to 2015 , the TFR of the ethnic minority population in 
northwestern China was above two while the TFR of the Han population was below 1.7. However, the TFR of the Han population rose to above 1.7 after the implementation of the Universal Two-child Policy in 2016.There was a stable increase in the size of ethnic minority populations. The growth rate of the ethnic minority population in Xinjiang Autonomous Region was greater than that of the Han population, keeping the proportion of the ethnic minority population to total population above $60 \%$ in Xinjiang. There was also a stable increase in the ethnic minority populations of Ningxia Autonomous Region and Qinghai Province.

\subsection{The population age structure in northwestern China featured population rejuvenation coupled with population aging}

From 2010 to 2020 , there was an increase in the elderly and adolescent populations in northwestern China, but a decrease in the working-age population. From 2010 to 2016, the total dependency ratio in northwestern China was slightly lower than the national level, and the gap widened from 2017 to 2020. During these eleven years, the old-age dependency ratio was lower than the national level, but the child dependency ratio was higher. This indicates an apparent rejuvenation trend and suggests advantageous conditions for labor force participation in the future.

\subsection{The biological sex structure of northwestern China fluctuated but was generally balanced, indicating a good trend for gender equality in northwestern China}

During the ten years from 2000 to 2010, the SRB in Shaanxi and Gansu Provinces gradually returned to balanced status, but the sex ratio remained at a higher level than the normal level. The SRB in Xinjiang Autonomous Region and Qinghai Province kept fluctuating within a range that was balanced, while the sex ratio approached balanced status. The SRB in Ningxia Autonomous Region remained slightly unbalanced throughout the years 2000-2010, but this was not enough to reverse the good trend in general population sex balance in northwestern China.

\subsection{The trend of urbanization is positive in northwestern China, but the level of urbanization is still significantly lower than the national level}

After 2010, the urbanization level in northwestern China increased from 44 to $54 \%$ in 2019, but was still lower than the national level of $60 \%$ in 2019.Among the five provinces and regions, the urbanization level of Shaanxi Province and Ningxia Autonomous Region were relatively high and approaching the national level, but the levels in Xinjiang Autonomous Region and Gansu Province were relatively lower (around 40\%). The urbanization level in Qinghai Province was between the higher levels in Shaanxi and Ningxia and the lower levels in Xinjiang and Gansu.

In summary, the population dynamics in northwestern China have apparent local characteristics compared with other provinces and regions. The lands of northwestern China are vast, but the population density is low, and the area is viewed 
as sparsely populated. However, because policies friendly to ethnic minorities have supported development of the area, the total population of northwestern China now exceeds 100 million. The ethnic minority population is increasing faster than the Han population, which has resulted in an advantageous situation with respect to population rejuvenation and indicates there will be ample human resources to support the future development of northwestern China. The movement towards gender equality will lead to a progressive environment and help in the future development of northwestern China, while the lower urbanization level offers ample space for the future economic development of northwestern China.

Funding This study is supported by China's National Social Science Foundation (Grant No: 20ARK007).

\section{Declarations}

Conflict of interest The authors declare that they have no competing interests.

Open Access This article is licensed under a Creative Commons Attribution 4.0 International License, which permits use, sharing, adaptation, distribution and reproduction in any medium or format, as long as you give appropriate credit to the original author(s) and the source, provide a link to the Creative Commons licence, and indicate if changes were made. The images or other third party material in this article are included in the article's Creative Commons licence, unless indicated otherwise in a credit line to the material. If material is not included in the article's Creative Commons licence and your intended use is not permitted by statutory regulation or exceeds the permitted use, you will need to obtain permission directly from the copyright holder. To view a copy of this licence, visit http://creativecommons.org/licen ses/by/4.0/.

\section{References}

Arsdale, P. (1978). Population dynamics among Asmat hunter-gatherers of New Guinea: Data, methods, comparisons. Human Ecology, 6(4), 435-467.

Brea, J. A. (2003). Population Dynamics in Latin America. Population Reference Bureau.

Calhoun, J. B. (1952). The social aspects of population dynamics. Journal of Mammalogy, 33(2), $139-159$.

Chalmers, L., \& Joseph, A. (2010). Population dynamics and settlement systems. New Zealand Geographer, 53(1), 14-21.

He, D. et al. (2018) China fertility status report, 2006-2016: an analysis based on 2017 China fertility survey. Population Research, 42(06):35-45

Hinde, A. (2002). Demographic Perspectives on Human Population Dynamics. Cambridge University Press.

Iburg, K. M. (1999). Inuit population dynamics: A demographic analysis of North Greenland. Canadian Studies in Population, 26, 141-158.

Jorgenson, A. K., \& Burns, T. J. (2007). Effects of rural and urban population dynamics and national development on deforestation in less-developed countries, 1990-2000. Sociological Inquiry, 77(3), 460-482.

Li, W., \& Liu, G. (2013). The reaserch about the conditions of the population distribution of XPCC and the Suggestions. Northwest Population Journal, 34(01), 83-89.

Nobles, J., Frankenberg, E., \& Thomas, D. (2015). The effects of mortality on fertility: Population dynamics after a natural disaster. Demography, 52(1), 15-38.

Yuan, X. et al. (2019). Fertility levels and trends in China's ethnic minority provinces, 2006-2016: based on 2017 China fertility survey. Population Research, 43(02):61-69. 

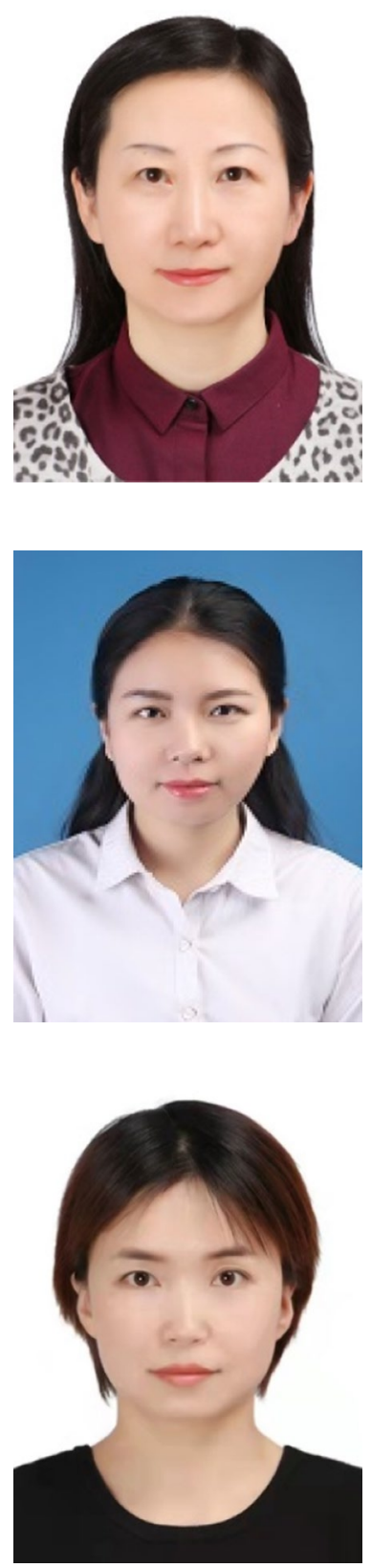

Xueyan Yang Ph.D, professor and director of Institute for Population and Development Studies, School of Public Policy and Administration, Xi'an Jiaotong University, Xi'an China.
Wanxin Li Ph.D candidates of Institute for Population and Development Studies, School of Public Policy and Administration, Xi'an Jiaotong University, Xi' an China.
Wen Jing Ph.D candidates of Institute for Population and Development Studies, School of Public Policy and Administration, Xi'an Jiaotong University, Xi' an China, and an editor of Shaanxi Provincial Party School. Her main research interests are public policy and population development. 

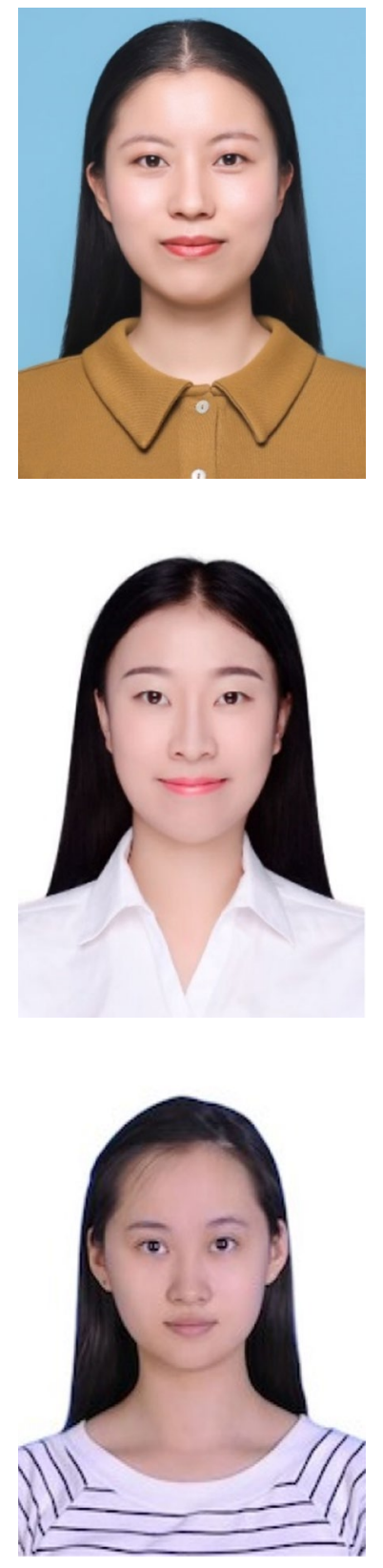

Chezhuo Gao Ph.D candidates of Institute for Population and Development Studies, School of Public Policy and Administration, Xi'an Jiaotong University, Xi'an China. Her main research interests are family policy and gender equality.

Rui Li Ph.D candidates of Institute for Population and Development Studies, School of Public Policy and Administration, Xi' an Jiaotong University, Xi' an China.

Yuqi He Master degree student of Institute for Population and Development Studies, School of Public Policy and Administration, Xi' an Jiaotong University, Xi'an China. 